\title{
Students' Perception and Experience of Massive Open Online Courses in Mongolia
}

\author{
Otgontsetseg Sukhbaatar'1, Lodoiravsal Choimaa², Tsuyoshi Usagawa ${ }^{1}$ \\ ${ }^{1}$ Graduate School of Science and Technology, Kumamoto University, Kumamoto, Japan \\ ${ }^{2}$ School of Engineering and Applied Sciences, National University of Mongolia, Ulaanbaatar, Mongolia \\ Email: otgon@st.cs.kumamoto-u.ac.jp, lodoiravsal@num.edu.mn, tuie@cs.kumamoto-u.ac.jp
}

How to cite this paper: Sukhbaatar, O., Choimaa, L., \& Usagawa, T. (2018). Students' Perception and Experience of Massive Open Online Courses in Mongolia. Creative Education, 9, 1818-1828. https://doi.org/10.4236/ce.2018.912132

Received: August 21, 2018

Accepted: September 15, 2018

Published: September 18, 2018

Copyright () 2018 by authors and Scientific Research Publishing Inc. This work is licensed under the Creative Commons Attribution International License (CC BY 4.0).

http://creativecommons.org/licenses/by/4.0/

(c) (i) Open Access

\begin{abstract}
E-learning can be a potential solution to educational inequality problem in developing countries, like Mongolia, with vast land and sparse population. With the introduction of Massive Open Online Courses (MOOCs), some impressive cases bring the attention of the public towards it. But there is no specific evidence that shows Mongolian students' experiences related to these online courses yet. Purpose of this study was to examine Mongolian students' MOOC perception and experience, especially influence of access, skills, and preferences in their practice. We used a 15-item questionnaire and results were based on 6846 students' responses. The study population consists of undergraduate students of the National University of Mongolia and high school students from 8 schools in Ulaanbaatar city. There was a significant difference between university and high school students in the awareness and enrollment rates. $47 \%$ of the students have heard of MOOCs and 2518 respondents (37\%) had an experience of taking MOOCs. Our results show that students have a doubt about MOOC's academical quality and consider it as an additional source of learning materials. The results of this study can be used to compare students' perception from other developing countries.
\end{abstract}

\section{Keywords}

Educational Technology, E-Learning Experience, MOOC, Students' Perception

\section{Introduction}

As a developing country, Mongolia did not pass over the movement toward e-learning. Mongolian universities pursue possibilities and try to penetrate blended and purely online courses into the curriculum to ensure equality of secondary education and expansion of higher-education outreach in rural areas. 
There are 330 remote sums (country subdivision) in Mongolia, within 1.5 million square kilometers land area, where schools and universities do not have enough teaching staffs, where educational inequality, inadequate ICT infrastructure are common issues. $97 \%$ of the Internet users concentrated in Ulaanbaatar and big cities, where the remaining small portion is for other areas of the country (ITPTA, 2016). In higher education, the majority of the students study in the capital, Ulaanbaatar city (MECSS, Statistics of the academic year of 2016-2017: higher education, 2017b).

Widespread usage of e-learning led one of the most fascinating developments in educational technology, a development of Massive Open Online Courses (MOOCs). Notable MOOC providers like Udacity, Coursera, and edX emerged in 2012, many universities around the world started developing MOOCs, free online courses available for everyone. MOOCs have been obtained huge popularity around the world and 2012 has been declared as the year of MOOCs by the New York Times (Pappano, 2012). Even though MOOC providers offered hundreds of courses, universities started to report the experience with their own implemented MOOCs. The Slovakian university offered two MOOCs to the public in 2013 and got a completion rate of 19.8\% (Melicherikova \& Piovarci, 2016). Since then, MOOCs have been a popular topic in educational institutions with discussions over MOOC's importance and academic merits. Whether it is opportunity or risk to higher education, the main significance of MOOCs is the learning opportunity for millions of people (Conole, 2013). Most importantly, MOOCs are proclaimed as a solution for providing high-quality education for developing countries, like Mongolia. Even though the number of MOOCs and the number of participants are increasing rapidly, the portion of learners from developing countries in Asia and Africa is still low. The majority of rural areas in those countries have the very limited infrastructure to efficiently accommodate students' MOOC activity (Liyanagunawardena, Williams, \& Adams, 2013). Also, there can be other reasons, for example, ICT literacy, language barrier or lack of awareness of the concept itself. It is questionable whether people from developing countries have a notion of MOOC and access possibilities to take MOOCs.

The purpose of this study is to examine Mongolian students' awareness, experience and perception toward MOOCs. Specifically, we seek to explore motivation and barriers for MOOC enrollment and how students' computer access and ICT literacy affect their online learning experiences. In this paper, we present results from the survey, covering one university and eight secondary schools.

\section{Literature Review}

The number of studies related to e-learning has increased dramatically over the last decade. Since MOOC got its popularity in 2012, many studies have been conducted in order to examine students' experience of using MOOCs through quantitative and qualitative methods. A study sought to explore students' state of knowledge and use of MOOCs in Georgian university reported that awareness 
and usage are quite low and the majority of the students never took any MOOCs before (Muzafarova \& Kaya, 2014). Similar results are obtained from another developing country, where the majority of the students were not aware of MOOCs or MOOC providers (Aboshady et al., 2015). Understanding learners' experience, current state, and motivation will give an opportunity to set the direction and efficient planning for the future.

When it comes to enrollment and usage, a study which examined condition in Columbia, Phillippines and South Africa showed completion rate of 30\%, which is far higher compared to developed countries' cases reported to be less than $10 \%$ (Garrido et al., 2016). Through an examination of students' awareness and perception, it is suggested that positive experience can lead to active participation (Aboshady et al., 2015). While others suggest that course accreditation and expectation may have a strong influence in retention (Cole \& Timmerman, 2015).

A retention is the main problem that MOOC providers are facing and reported problems for high dropout rate are usually pedagogical and technological issues (Atiaja \& Proenza, 2016). There are many studies reported MOOC experience in terms of learner's motivation and preference. Learners' motivation for enrollment has been examined and identified the difference in their behavior of self-regulated learning strategies dependent on their motivation and goal setting (Littlejohn, Hood, Milligan, \& Mustain, 2016). Students preferred face-to-face discussion over the online discussion, even they acclaim MOOCs as a good self-paced learning material (Bruff, Fisher, McEwen, \& Smith, 2013). Examining students' experience through survey and interview after participation in a MOOC suggested that many competency factors, such as communication and self-directed learning skills, may affect students' engagement and retention in MOOC learning (Abeer \& Miri, 2014). A number of studies have suggested that reward or any kind of incentives can increase student engagement (Anderson, Huttenlocher, Kleinberg, \& Leskovec, 2014; Bruff, Fisher, McEwen, \& Smith, 2013). Even though an interest in the course content is the main factor for MOOC completion, an examination of motivational variables suggested that also learners' self-confidence and perspective have an impact on completion rate (Wang \& Baker, 2015). Some studies suggest and encourage tutor's direct engagement in online discussions (Murray, 2014; Hone \& El Said, 2016). However, it is quite difficult or impossible to achieve with MOOC's large number of participants. Many researchers still looking deeper on motivations for enrollment, impact on engagement, retention, and completion of MOOCs.

\section{Method}

In this study, a quantitative approach was adopted. In order to investigate students' attitude toward MOOCs, a survey method was employed. Data analysis was performed using RStudio v1.0.136. We used a significance level alpha of 0.05 for statistical tests. 


\subsection{Participants and Data Collection}

A total of 6903 students involved in the study and 57 respondents' sheets were eliminated due to incomplete response, making total population of $6846 \mathrm{stu}-$ dents. Participants consist of the following two groups:

- 6119 undergraduate students of National University of Mongolia (NUM), one of the biggest and oldest universities in Mongolia.

- 727 students from 8 high schools (7 public and 1 private) in 6 different districts of Ulaanbaatar city.

NUM students were asked to fill out the questionnaire when they logged into the university information system and voluntarily filled out the questionnaire. The population of NUM participants could include students from all 3 campuses (main campus in Ulaanbaatar city and two branch schools in Zavkhan, Orkhon provinces) and covered approximately $35 \%$ of the total undergraduate student pool of the university. Response for all questionnaire items was required for survey submission and anonymous responses with demographic information of department, gender and study year were provided.

High school students have filled the paper-based version of the questionnaire which distributed during regular class activities and gave them enough time that the students can answer at their own pace. Students selected in a random manner.

University student population covers about $4 \%$ of the total students in Mongolia (MECSS, Statistics of the academic year of 2016-2017: higher education, $2017 \mathrm{~b})$. Samples of school pupils include $1.9 \%$ of the total high school students in Ulaanbaatar city, which covers 8 out of 179 high schools (MECSS, Statistics of the academic year of 2016-2017: general education, 2017a).

\subsection{Research Instrument}

The questionnaire consists of 11 items with 5-point Likert-type scale responses (strongly agree, agree, neutral, disagree and strongly disagree) and 4 items to gather detailed information. Questions developed through literature review and discussions.

\section{Results}

\subsection{MOOC Awareness}

Participants' affiliation with their state of knowledge, the experience of enrollment and completion of MOOCs are presented in Table 1. Around half of the participating NUM students $(3007,49.1 \%$ ) were aware of MOOCs, where $75.4 \%$ (4613) stated they had a computer with an Internet connection at home. NUM students showed higher awareness compared to high school students $(49.1 \%$, $28.2 \%, \mathrm{p}<0.001)$. Moreover, NUM students showed a higher rate of knowledge compared to other developing country's case, where only $21.7 \%$ of the undergraduate students in Egypt knew about MOOCs (Aboshady et al., 2015). For high school students, only $28.2 \%$ of them knew what MOOC is. The awareness 
of students from private and public high schools showed a difference $(43.9 \%$, $24.8 \%, \mathrm{p}=0.04)$. One of the reasons for this difference can be students' computer access, since there was a significant difference between private and high school students in the availability of a computer at home $(89 \%, 73 \%, \mathrm{p}<0.001)$. Also, it can be due to students' language ability, which is generally students from private schools have better language skills. Students which had a prior knowledge of MOOCs had better computer access rate $(\mathrm{m}=4.29$, $\mathrm{sd}=1.15) \mathrm{com}$ pared to students who had not $(\mathrm{m}=3.76, \mathrm{sd}=1.40, \mathrm{p}<0.001)$. Also, students with knowledge of MOOC had a better confidence in computer skills $(\mathrm{m}=4.50$, $\mathrm{sd}=0.74)$ and electronic communication ability $(\mathrm{m}=4.48$, $\mathrm{sd}=0.77)$ than students were not aware of MOOC $(\mathrm{p}<0.001)$.

Descriptive statistics of students' MOOC perception is shown in Table 2. It includes only students who were aware of the MOOC concept. The majority of the students think that MOOCs are a good source of knowledge and has a good influence on their learning experience. However, it also shows that students have a doubt about whether MOOCs are scholarly enough and convenient to use.

\subsection{Enrollment Motives and Barriers}

The majority of (78.4\%) of the students who were aware of MOOCs, took the course to try and $78.6 \%$ of them stated they completed at least on MOOC (Table 1). Students' motives for enrolling MOOCs were examined and responses from 2518 students, who used MOOC before is shown in Table 3. The main motive for enrollment was curiosity, where $37.5 \%$ of the students responded that they took a MOOC out of curiosity. One-fourth of the students enrolled MOOCs according to lecturer's suggestion. Most students (40.5\%) tried $1-2$ MOOCs and $11.6 \%$ of the students claimed that they took more than 5 MOOCs.

There were 694 students who were aware of MOOCs but didn't try to take the course. They stated that main reasons for not using MOOC are lack of spare time (17.0\%), preference for the physical classroom (18.7\%), lack of face-to-face communication (14.4\%) and unfamiliarity with online learning environments (11.2\%).

\subsection{Completion Barriers}

We sought to explore what are the main barriers for MOOC completion and results are shown in Table 4. Students stated as main reasons couldn't complete the course were time management issues, study overload and the particular subject had learned.

There was a significant difference between high school and university students in terms of enrollment $(69.3 \%$ and $79 \%, \mathrm{p}<0.001)$ and completion rate $(69.7 \%$, $79.2 \%, \mathrm{p}=0.002)$, that university students show more interest to enroll and complete to achieve the certificate. It suggests that increasing students awareness can lead to increased usage of these courses. The majority of the students who had knowledge about MOOCs seems enrolled and tried the courses. 
Table 1. Demographic characteristics with awareness, enrollment, and completion.

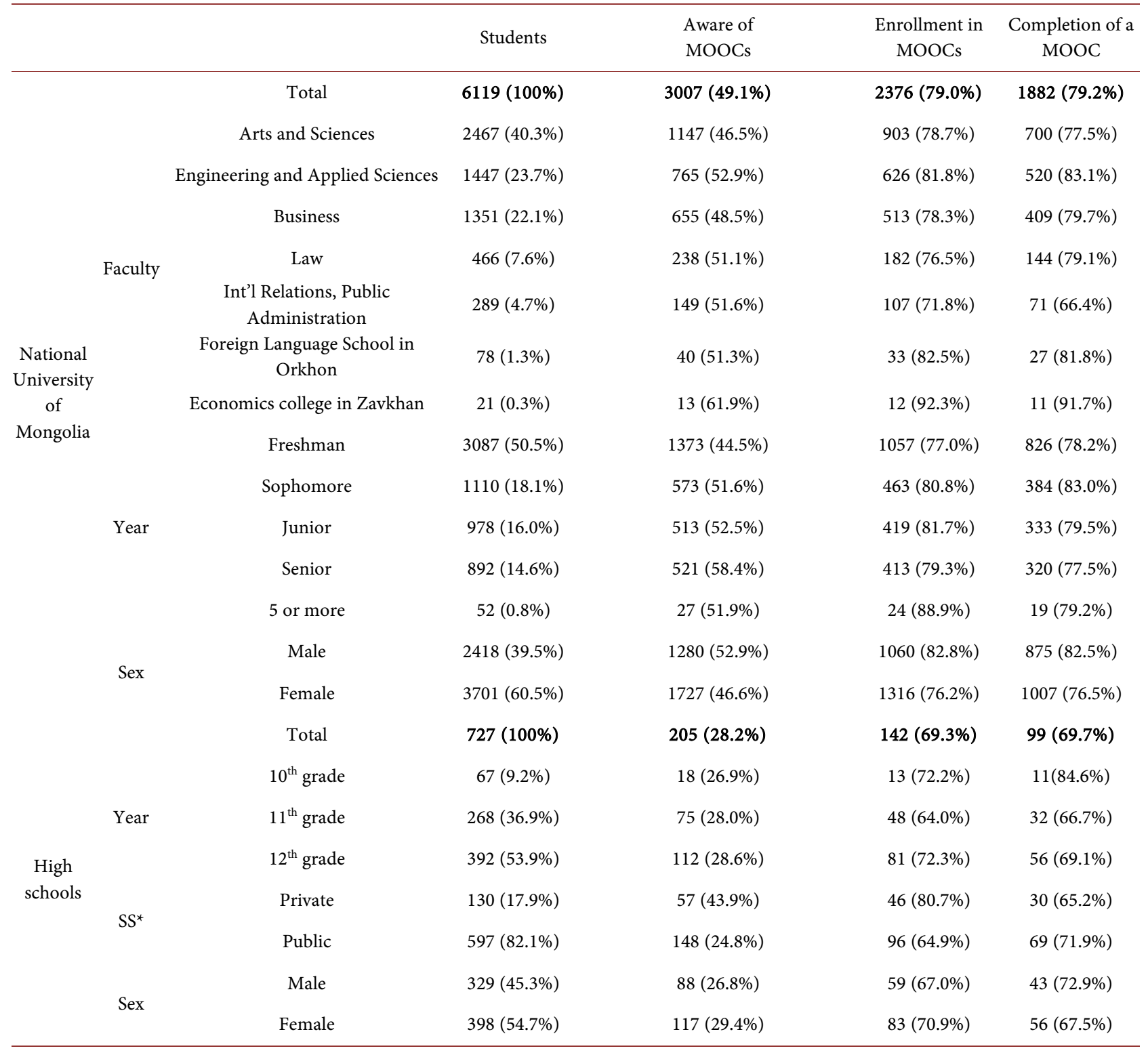

* SS: sources of support.

Table 2. Descriptive analysis of MOOC perception.

\begin{tabular}{ccccc}
\hline \multirow{2}{*}{ Items } & \multicolumn{2}{c}{ University, $\mathrm{N}=3007$} & \multicolumn{2}{c}{ High school, $\mathrm{M}=205$} \\
\cline { 2 - 5 } & mean & $\mathrm{sd}$ & mean & sd \\
\hline $\begin{array}{c}\text { MOOCs are a good source of } \\
\text { knowledge and information }\end{array}$ & 4.15 & 0.86 & 3.92 & 0.82 \\
$\begin{array}{c}\text { MOOCs have a good influence on } \\
\text { their learning experience }\end{array}$ & 4.21 & 0.84 & 3.98 & 0.81 \\
$\begin{array}{c}\text { MOOCs are convenient to use } \\
\begin{array}{c}\text { MOOCs are equal to formally taught } \\
\text { for-credit course }\end{array}\end{array}$ & 2.53 & 1.22 & 2.89 & 1.06 \\
\hline
\end{tabular}

$(\mathrm{p}<0.001)$ 
Table 3. Motives for enrollment $(\mathrm{N}=2518)$.

\begin{tabular}{cc}
\hline Reason & Number of students \\
\hline Curiosity & $945(37.5 \%)$ \\
Instructor asked to enroll the course & $630(25.0 \%)$ \\
Improve knowledge of a related subject & $472(18.7 \%)$ \\
Enhancement of specific skills & $380(15.1 \%)$ \\
\hline
\end{tabular}

Table 4. Barriers for MOOC completion $(\mathrm{N}=2518)$.

\begin{tabular}{cc}
\hline Reason & Number of students \\
\hline Time management & $964(38.3 \%)$ \\
Overload at study & $667(26.5 \%)$ \\
The particular subject had learned & $310(12.3 \%)$ \\
No face-to-face interaction & $143(5.7 \%)$ \\
Lack of self-study skills & $87(3.5 \%)$ \\
Others & $347(13.8 \%)$ \\
\hline
\end{tabular}

\subsection{Characteristics of MOOC Users}

As shown in Table 1, 37\% (2518) of the total respondents had previous experience with MOOCs and $44 \%$ of them are male. Majority of the students (85\%) have a computer with Internet connection at home. A portion of MOOC user students with respect to computer access and self-assessed ICT skills has shown in Figure 1. As it may seem that most important factor for online learning is computer access, but $59 \%$ of the students who had a computer with Internet connection at home, didn't have an experience of using MOOCs. On the other hand, $23 \%$ of the students, who don't have a computer at home, already tried MOOCs.

As shown in Figure 1, high confidence in ICT literacy results in high chance to participate in online learning activities. For example, half (49\%) of the students who has a strong confidence (with response of "strongly agree") in basic computer skills, had experience of open online courses, where only $8 \%$ of the students who had evaluated themselves as noncompetent (with response of "strongly disagree") tried MOOCs.

\section{Discussion}

MOOCs are considered as a solution for providing high-quality education for developing countries. However, the portion of participants from developing countries is low, an even number of MOOCs are increasing rapidly. In developing country, for example in Egypt, it has shown that majority of the students (only one-fifth has heard of) didn't know about MOOCs (Aboshady et al., 2015). But our study reported that about a half (49\%) of the university students were aware of the MOOC concept, which is quite high compared to Egypt's case. 


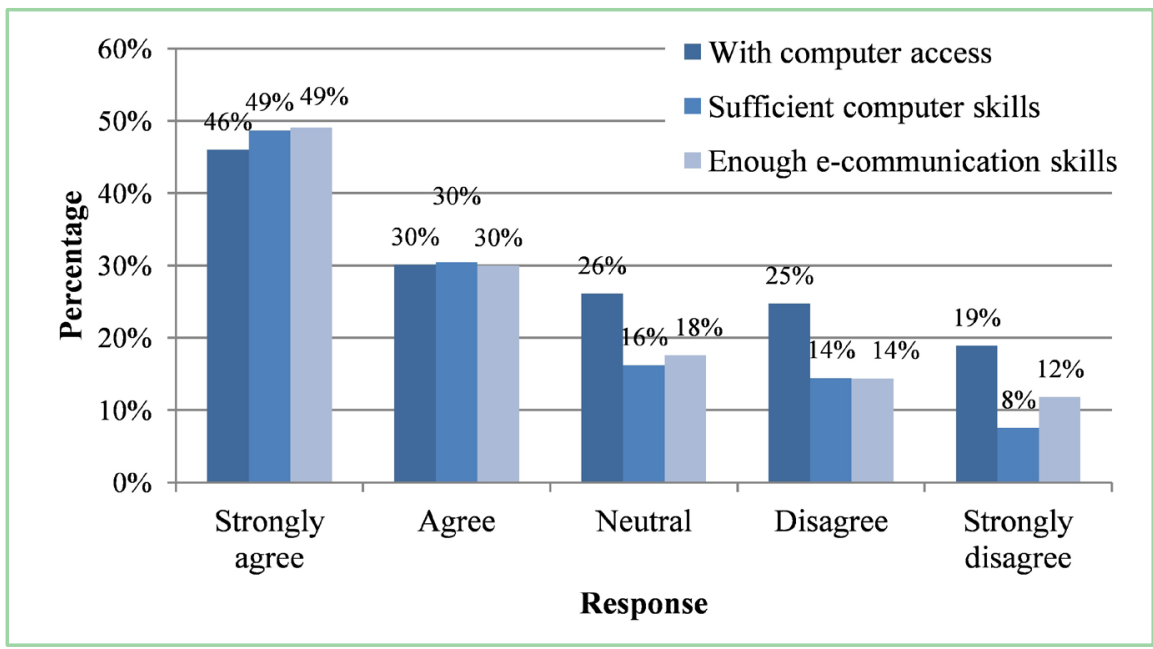

Figure 1. A portion of MOOC user students in terms of ICT skills.

MOOC providers need to make an effort to raise awareness of the young generation, especially from developing countries. Learners from developing countries can be one of the potential active users due to lack of available, high-quality course contents in their home countries.

As a developing country, where ICT infrastructure and access is still in the insufficient state, our first consideration for MOOC experience in Mongolian students was computer access and ICT literacy. In 2015, Mongolia's ICT access index has reached 4.97 (world average of 5.53), where it was 3.98 in 2010 (ITPTA, 2016). Our results showed that around $75.4 \%$ of the total responding students had a computer access with an Internet connection at home. We emphasize that it was more than we expected, as a percentage of households with internet access in Mongolia, is only 29\% (world average of 43.94) and $91.4 \%$ of the total Internet subscribers use wireless communications for mobile devices (ITPTA, 2016). However, it should be noted that the survey took the place in the capital city of Mongolia, where ICT condition is far better compared to rural areas. It was surprising that $62.6 \%$ of the students from countryside areas (branch schools of Orkhon and Zavkhan province) had a computer with Internet connection at home. In those areas, Internet access and connection speed are relatively low compared to cities (ITPTA, 2016). But, it can be due to a small number of respondents (99 students) and it's more likely that students with computer access and Internet connection at home responded to the survey.

As expected, better ICT ability lead to more online learning experiences, proving the belief that majority of the e-learning users have higher confidence in ICT skills. Results indicate that many students have a doubt about the quality of the MOOCs and unfamiliarity with the online learning environment. Due to these reasons, students tend to not enroll MOOCs or not engage persistently. Students usually see MOOCs as an additional material for information, which results in high enrollment at first, but not eager to spend time and effort on the course materials and assignments. Furthermore, no accreditation and students' 
preference for physical classroom communication may result in low completion rates reported in the literature.

About one-third $(2518,37 \%)$ of the students had previous experience of using MOOCs. First dominant reason for using MOOCs is found to be curiosity, which can be the result of MOOC's popularity for the last couple of years in Mongolia. It was impressive to see that $18.7 \%$ of the students chose to use MOOC to improve their knowledge. It's getting common to use MOOCs as additional learning material for on-campus courses, where $25 \%$ of the students claimed that their instructor asked to enroll the MOOC.

Results claim that MOOCs tend to have a positive influence on students' study. However, results suggest that students mostly enroll the MOOCs for curiosity, go through the course contents several times and give up. Students stated as the main limitation for completion was overload at the study and couldn't make a time for enrolled courses.

Majority of the responding students (73.8\%) expressed their willingness to take this kind of open online courses if Mongolian university offers one.

\section{Strength and Limitation}

The major strength of this study is a large population of 6846 students, where it covered one-third of the total undergraduate student pool of the National University of Mongolia, the oldest and one of the biggest universities in Mongolia. Moreover, it included heterogeneous student population from 7 public and one private high schools in various districts of the Ulaanbaatar city, the capital of Mongolia.

The limitation of the study is that it considered the only perception of the participating students and the results cannot be generalized to all students in Mongolia. However, we believe that the study population can be a representative sample and outcome of this study can report initial sights into Mongolian students' state and perception.

\section{Conclusion}

The main purpose of this study was to examine Mongolian students' MOOC perception and influence of access, skills, and preferences in e-learning experience. Findings suggest that educators need to more concentrate on spreading the knowledge of the advantages of educational technologies, facilitation and efficient delivery of the courses. As the students eager to try and engage even there is a deficiency of access and skills, it's important to make them have successful first experience for better engagement.

To our best knowledge, it is the first study with a large population from Mongolia and we believe that the results can make a handful of contribution for understanding students' perception in a developing country.

Further research is required to fully understand students, the experience of MOOCs in Mongolia and involve a representative number of students from other 
universities. In addition, it is crucial to explore the factors which affect student's decision to engage or drop the MOOCs. It will allow educators to recognize the issues and increase the educational value of MOOCs. Therefore, a comprehensive study to reveal possible factors for retention is needed from MOOC learners.

\section{Acknowledgements}

Part of this work was supported by JSPS KAKENHI Grant-in-Aid for Scientific Research 25280124 and 15H02795. The authors would like to thank the Students Affairs Office and the Center for Management of Information Technology of the National University of Mongolia, for making this research possible.

\section{Conflicts of Interest}

The authors declare no conflicts of interest regarding the publication of this paper.

\section{References}

Abeer, W., \& Miri, B. (2014). Students' Preferences and Views about Learning in a MOOC. Procedia-Social and Behavioral Sciences, 152, 318-323. https://doi.org/10.1016/j.sbspro.2014.09.203

Aboshady, O. A., Radwan, A. E., Eltaweel, A. R., Azzam, A., Aboelnaga, A. A., Hashem, H. A., et al. (2015). Perception and Use of Massive Open Online Courses among Medical Students in a Developing Country: Multicentre Cross-Sectional Study. BMJ Open, 5, e006804. https://doi.org/10.1136/bmjopen-2014-006804

Anderson, A., Huttenlocher, D., Kleinberg, J., \& Leskovec, J. (2014). Engaging with Massive Online Courses. Proceedings of the 23rd International Conference on World Wide Web, Seoul, Korea, 7-11 April 2014, 687-698.

Atiaja, L. N., \& Proenza, R. S. (2016). MOOCs: Origin, Characterization, Principal Problems and Challenges in Higher Education. Journal of E-Learning and Knowledge Society, 12, 65-76.

Bruff, D., Fisher, D., McEwen, K., \& Smith, B. (2013). Wrapping a MOOC: Student Perceptions of an Experiment in Blended Learning. Journal of Online Learning and Teaching, 9, 187-199.

Cole, A. W., \& Timmerman, C. E. (2015). What Do Current College Students Think about MOOCs. MERLOT Journal of Online Learning and Teaching, 11, 188-201.

Conole, G. (2013). MOOCs as Disruptive Technologies: Strategies for Enhancing the Learner Experience and Quality of MOOCs. Revista de Educación a Distancia, 39, 1-17.

Garrido, M., Koepke, L., Andersen, S., Mean, A. F., Macapagal, M., \& Dalvit, L. (2016). An Examination of MOOC Usage for Professional Workforce Development Outcomes in Colombia, the Philippines, \& South Africa. Seattle: Technology \& Social Change Group, University of Washington Information.

Hone, K. S., \& El Said, G. R. (2016). Exploring the Factors Affecting MOOC Retention: A Survey Study. Computers \& Education, 98, 157-168. https://doi.org/10.1016/j.compedu.2016.03.016

ITPTA. (2016). White Paper: ICT Development of Mongolia. Ulaanbaatar: Information Technology, Post and Telecommunications Authority.

Littlejohn, A., Hood, N., Milligan, C., \& Mustain, P. (2016). Learning in MOOCs: Motiva- 
tions and Self-Regulated Learning in MOOCs. Internet and Higher Education, 29, 40-48. https://doi.org/10.1016/j.iheduc.2015.12.003

Liyanagunawardena, T., Williams, S., \& Adams, A. (2013). The Impact and Reach of MOOCs: A Developing Countries' Perspective. E-Learning Papers, 33, 38-46.

MECSS. (2017a). Statistics of the Academic Year of 2016-2017: General Education. Ministry of Education, Culture, Science and Sports of Mongolia.

MECSS. (2017b). Statistics of the Academic Year of 2016-2017: Higher Education. Ministry of Education, Culture, Science and Sports of Mongolia.

Melicherikova, Z., \& Piovarci, A. (2016). Experience with Massive Open Online Courses in Slovakia. Journal of E-Learning and Knowledge Society, 12, 149-155.

Murray, J.-A. (2014). Participants' Perceptions of a MOOC. Insights: The UKSG Journal, 27, 154-159. https://doi.org/10.1629/2048-7754.154

Muzafarova, T., \& Kaya, E. (2014). Survey of Awareness of Massive Open Online Courses (MOOC): A Case of International Black Sea University Students, Georgia. Journal of Education, 3, 15-19.

Pappano, L. (2012). The Year of the MOOC. The New York Times.

Wang, Y., \& Baker, R. (2015). Content or Platform: Why Do Students Complete MOOCs? MERLOT Journal of Online Learning and Teaching, 11, 17-30. 